\title{
Assessing the Procedures Followed to Avoid the Risk of Food Allergies in the Food and Beverage Sector within Lodging Establishments: The Case of Red Sea Governorate Mostafa Attia Abd El-Fattah ${ }^{1} \quad{ }^{2}$ Mohamed Abdel Moneim Saleh \\ ${ }^{1}$ Faculty of Tourism and Hotel Management, Beni-Suef University ${ }^{2}$ Environmental, Microbiological and Food Safety Consultant in Egyptian Tourism Federation - Lecturer in Future Academy - El Hijaz
}

\begin{abstract}
A food allergy can be explained as an immune system response to a food that the body mistakenly believes is harmful. Once the immune system decides that a particular food is harmful, it creates specific reactions to fight it. The next time the individual eats that food, the immune system releases massive amounts of chemicals, including histamine, in order to protect the body. These chemicals trigger a cascade of allergic symptoms that can affect the respiratory system, gastrointestinal tract, skin, and cardiovascular system and reactions can be deadly (The Food Allergy \& Anaphylaxis Network, 2010).

Several studies illustrated that many of the hotels suffer of the problem or risks that occurring, including the symptoms of allergies to some of the guests so there are many of the actions taken by hotels to avoid this allergies, hence the importance of this research, which is based on the assessing the procedures followed to avoid the risk of food allergies in the food and beverage sector within lodging establishments of Red Sea Governorate, in order to access the best recommendations and suggestions that could contribute to the control of this type of risk so as to ensure the safety of the guests, as well as to avoid the problems that occur for hotels and the hospitality industry in general. In order to reach these goals has been to take advantage of using the two research tools, first Personal interviews with the number of executive chef and food and beverage managers, secondly designed model of personal observations check list that help to evaluate the procedures that already taken inside the hotel in order to control food allergies risk. Finally, it is worth mentioning that due to many obstacles, including difficult access to all Red Sea Governorate hotels destination in addition to the elements of time and cost therefore, the investigated hotels are limited to some of three, four and five star hotels in Red Sea Governorate destination (Hurghada, Quseir and Marsa Alam).
\end{abstract}

Keywords: Food allergy - Food and beverage - hotels - Cross contact - Managing food allergy

\section{Introduction}

It is worth mentioning that could not find reliable figures to explain the numbers of people suffering from the risk of food allergies in Egypt, especially in the Egyptian lodging establishments. While, American College of Allergy, Asthma \& Immunology (2014) mentioned that there are more than 50 million Americans having an allergy of some kind. Food allergies are estimated to affect $4 \%$ to $6 \%$ of children and $4 \%$ of adults. Food allergy symptoms are most common in babies and children, but they can appear at any age. Also, The Food Allergy \& Anaphylaxis Network (2010) declared that there is no direct cure for a food allergy till now; just avoidance was the only way to prevent the allergic. While, Mayo Clinic Staff (2014) highlighted that the body's immune system keeps the health by fighting off infections and other dangers to good health. A food allergy reaction when immune system overreacts to a food or a substance in a food, identifying it as a danger and triggering a protective response.

American College of Allergy, Asthma \& Immunology (2014) mentioned that the symptoms of a food allergy can ranges from mild to severe. Just because an initial reaction causes few problems doesn't mean that all reactions will be similar; a food that triggered only mild symptoms on one occasion may cause more severe symptoms at another time. Meanwhile, 
Formanek (2001) and McKeever (2014) declared that food which can cause an adverse reaction, are eight types of food that represents 90 percent of all reactions:

- Eggs

- Milk

- Peanuts

- Tree nuts
- Shellfish

- Wheat

- Soy

Mayo Clinic Staff (2014) added that certain seeds, including sesame and mustard seeds (the main ingredient in the condiment mustard), also are common food allergy triggers and considered a major allergen in some countries.

\section{Review of literature}

\section{The concept of food allergy}

Food allergies are becoming more common because there has been an increase in severe food allergy cases in the last 10 years, mostly driven by peanut, tree nut and other allergens. Food allergies happen when a sensitive person eats, inhales, or comes into contact with even little amounts of certain foods. These reactions happen with exposure to food allergens and it can be very mild or may be life threatening (Associates MD, 2017). Also, Mayo Clinic Staff (2014) mentioned that food allergy is an immune system reaction that occurs soon after eating a certain food. Even a tiny amount of the allergy causing food can trigger signs and symptoms such as digestive problems, hives or swollen airways. In some people a food allergy can cause severe symptoms or even a life threatening reaction known as anaphylaxis.

On the other hand, Taylor and Hefle (2001); FDA (2004); Nowak-Wegrzyn (2013); and American College of Allergy, Asthma \& Immunology (2014) defined food allergy as "An allergy occurs when your body's natural defenses overreact to exposure to a particular substance, treating it as an invader and sending out chemicals to defend against it". Bennion and Scheule (2004) also, defined "Food allergy is an abnormal immune response to components in food (usually proteins). Symptoms can include gastrointestinal, cutaneous, and respiratory responses or other symptoms such as laryngeal edema, anaphylactic shock, or hypotension".

\section{Symptoms of food allergy}

Food safe for the majority of people but may be unsafe for individuals who are allergic to specified foods. The food allergies are characterized by abnormal immune system response to naturally occurring proteins in food. Food allergy symptoms are varied and can include gastrointestinal, cutaneous, respiratory, or other symptoms. This is in additional to some individuals experience anaphylactic shock that can result in death within minutes of consuming an offending food unless prompt medical attention is received (Bennion and Scheule, 2004; and Nowak-Wegrzyn, 2013). Meanwhile, Brostoff and Gamlin (2000) and Sicherer (2013) mentioned that most food related symptoms occur within two hours of ingestion; often they start within minutes. In some very rare cases, the reaction may be delayed by four to six hours or even longer. Meanwhile, Sicherer (2006); and Wood (2007) declared that symptoms of an allergic reaction may involve the skin, the gastrointestinal tract, the cardiovascular system and the respiratory tract. They can suffer in one or more of the following symptoms:

- Vomiting and/or stomach cramps

- Shortness of breath

- Shock or circulatory collapse

- Tight, hoarse throat; trouble swallowing

- Swelling of the tongue, affecting the ability to talk or breathe
- $\underline{\text { Hives }}$

- Wheezing

- Repetitive cough

- Dizziness or feeling faint

- Weak pulse 
- Pale or blue coloring of skin

\section{Managing food allergies in hotels}

The Food Allergy \& Anaphylaxis Network (2010) pointed out that hotels must keep in mind that food allergies are type of risks and syndromes, not food preferences. The best way to minimize food allergy risks for guests is to create a written plan for handling guests with food allergies that all staff members must follow. When creating the plan, the following questions have to be considered

- Who will answer guests' questions regarding menu items?

- Who will be responsible for checking the ingredients used in menu items?

- What steps should take by kitchen staff to avoid cross-contact?

- How should staff members handle an allergic reaction?

When planning the food and beverage menus for hotel guests, the chef must think of the danger of any food allergies. All kitchen and service staff's must be informed of the contents of the dishes (Foskett, Ceserani, and Kinton, 2003). The Food Allergy \& Anaphylaxis Network (2010) mentioned that ideally, the manager should be the point person for all food allergy questions from guests or kitchen and service staff's. Meanwhile, FARE (2016) added that all of food and beverage staffs must be aware with the concept of cross-contact: occurs when an allergen is inadvertently transferred from a food containing an allergen to a food that does not contain the allergen. FDA (2017) declared that cross-contact occurs when the proteins from two or more foods mix for example, during cooking or while serving the foods. The protein is the part of the food that causes the food allergy. Even a tiny amount of an allergy causing food is enough to cause an allergic reaction in some people. Therefore, precautions must be taken to avoid cross contact from foods to which a patient is allergic. But, Bennion and Scheule (2004) noted that cooking does not reduce or eliminate the chances of a person with a food allergy having a reaction to the food eaten.

McKeever (2014) highlighted that the attention and follow-up guests it only takes a few extra minutes to handle a special request or to answer questions from a guest with food allergies. This is time well spent, as it could prevent situations all hotels would rather avoid, such as a lawsuit or an allergic reaction that results in an ambulance arriving at the restaurant during peak dining hours. The Risk Management section provides guidance in creating a food allergy management program for the hotel. On the other hand, The Food Allergy \& Anaphylaxis Network (2006) mentioned that some hotels have the standards that staff must adhere to regarding timeliness of service. A cook or server who feels rushed to meet such standards may be more likely to take a shortcut that could result in an allergic reaction. Let employees know that when they are preparing food for a guest who has a food allergy, they may take a bit more time to ensure that a mistake is not made. Staff should verify the order to avoid making mistakes. If there is a mistake, they must discard the dish and make a new one. Also, McKeever (2014) added that guests with food allergies usually prefer to speak with employees face-to-face about their needs, for that employee should refer all questions or special requests directly to the manager, and may want to suggest that guests with special requests come inside to discuss ingredients and review a menu.

On the other hand The Food Allergy \& Anaphylaxis Network (2010) highlighted that food allergy training is a process that requires regular review, especially of procedures for handling an allergy emergency. Be sure new employees understand the food allergy policy, and train them to take food allergies seriously. Include food allergy information in new hire orientation. Provide information via brochures, videos, and posters. Develop a checklist of discussion points that managers can review with new employees before they begin serving guests. 


\section{Tips guest and suggested procedures to avoid food allergy risks}

There are many guidelines and suggested procedures to take into account to avoid the risks and problems of food allergies, and as follows:

- In order to provide top-notch service to customers and avoid potential liability, it is important to designate qualified and trained staff members to handle questions and requests from guests who have food allergies (Massachusetts Department of Health, 2010).

- When a guest identifies himself or herself as having a food allergy, the staff members should notify the manager on duty. The manager should answer any questions the guest may have about the menu items and ensure that the proper procedures are followed for this special meal. The manager or chef should be responsible for discussing ingredient information with the guest and for letting the guest know if ingredient information is not available. Although staff members can supply information on ingredients and preparation methods, the guest has the final say in what his or her menu selection will be (ByrdBredbenner and Maurer, 2007).

- The guests must be extra careful when eating outside. Service staffs (and sometimes the kitchen staff) may not always know the ingredients of every dish on the menu. Depending on sensitivity, even just walking into a kitchen or a restaurant can cause an allergic reaction (McKeever, 2014).

- The guests must tell the servers about their allergies and ask to speak to the chef, if possible. Stress the need for preparation surfaces, pans, pots and utensils that haven't been contaminated by allergen, and clarify with the restaurant staff what dishes on the menu are safe (National Institute of Allergy and Infectious Diseases, 2013).

- Individuals with food allergies need restaurants to provide them with accurate information about ingredients so they can make informed decisions about what to order from the menu. Incorrect or incomplete information puts these guests at risk for an allergic reaction (The Food Allergy \& Anaphylaxis Network, 2006).

- Avoid the food or ingredient that causing food allergy is the only way to avoid a reaction and reading ingredient labels for all foods is the key to maintaining control over the allergy (Basset, 2005).

\section{Research methods}

The purpose of this research was to assessing the procedures followed to avoid the risk of food allergies in the food and beverage sector within lodging establishments of red sea governorate, in order to access the best recommendations and suggestions that could contribute to the control that risk so as to ensure the safety of the guests, as well as to avoid the problems that occur for hotels and the hospitality industry in general. This part of the study includes limitations and study samples, as well as review of the research tools that used in this study, which are as follows:

1. Personal interviews with the number of executive chefs and food and beverage managers.

2. Personal observation checklist.

\section{Limitations}

Indubitably; it was too difficult to sample all hotels in Red Sea Governorate destination, because it is prohibitive in terms and conditions of cost, time and accessibility, also in addition to the difficulty of obtaining the approvals of the hotel managers' in order to facilitate the implementation of this research within their hotels. Therefore, the investigated hotels are limited to some of three, four and five star hotels in Red Sea Governorate destination (Hurghada, Quseir and Marsa Alam). 


\section{The Sample}

The research sample was chosen random stratified sample. According to the Egyptian Hotel Association (2016); and FreeHotelsGuide.com (2016) there are about 121 three, four and five star hotels in Hurghada (48 three star hotel, 49 four star hotel and 24 five star hotel), there are about 11 three, four and five star hotels in Quseir ( 5 three star hotel, 4 four star hotel and 2 five star hotel), and there are about 43 three, four and five star hotels in Marsa Alam (23 three star hotel, 17 four star hotel and 3 five star hotel). It should be noted that the sample of the study was limited to only two hotels of the category of three star, two four-star hotels and two five-star hotels which represents $10 \%$ of the total number of these categories in Red Sea Governorate destination was investigated (Representing 5\% of the total hotel categories study sample in Hurghada, representing 55\% of the total hotel categories in Quseir, and representing $14 \%$ of the total hotel categories in Marsa Alam). It should be emphasized that the small sample size of the research sample was result of many obstacles which including the opposition many hotel managers in addition to the time and cost.

\section{Research Instrumentations}

\section{1- Personal interviews}

Semi structured personal interviews were one of the main sources of evidence which represents one of the key aspects of this research. A thirty nine executive chef and food and beverage managers or their assistants were investigated in eighteen hotels in Red Sea Governorate destination (see Table 1). The overall purpose of these interviews is to assessing the procedures that followed to avoid the risk of food allergies in the food and beverage sector within lodging establishments of Red Sea Governorate. The personal interviews consisted of 15 questions that were designed and selected after reviewing a number of previous studies, references and scientific researches specialized in the field of food allergy, as well as browsing websites. The personal interviews was also reviewed by two experts in the field of hotel education as well as three experts in the field of quality and safety inspection of hotels on safety procedures and quality of services provided. Finally it has been completed personal interviews in the period between February and until May 2017. Also, for ethical considerations, the study was used coded names for the investigated hotels.

Table 1: List of the investigated hotels/destinations and number of interviewees in each hotel

\begin{tabular}{|l|l|l|}
\hline \multicolumn{3}{|c|}{ Hurghada: } \\
\hline PSHR 1H & 5 Star & 3 (Ex. Chef, Ex. Sous Chef and F\&B Manager) \\
\hline MRSEG 1H & 5 Star & 3 (Ex. Chef, Ex. Sous Chef and F\&B Manager) \\
\hline AA1H & 4 Star & 2 (Ex. Chef, and F\&B Manager) \\
\hline MIBR 1H & 4 Star & 2 (Ex. Chef, and Assistant F\&B Manager) \\
\hline HMBHR 1H & 3 Star & 2 (Ex. Chef, and Assistant F\&B Manager) \\
\hline HJV 1H & 3 Star & 2 (Sous Chef, and Assistant F\&B Manager) \\
\hline \multicolumn{2}{|c|}{ Quseir: } \\
\hline DBR 2Q & 5 Star & 2 (Ex. Chef, and F\&B Manager) \\
\hline RSR 2Q & 5 Star & 2 (Ex. Chef, and F\&B Manager) \\
\hline FBR 2Q & 4 Star & 2 (Ex. Chef, and F\&B Manager) \\
\hline MR 2Q & 4 Star & 2 (Ex. Chef, and F\&B Manager) \\
\hline MBR 2Q & 3 Star & 2 (Ex. Chef, and Assistant F\&B Manager) \\
\hline UBC 2Q & 3 Star & 2 (Ex. Chef, and F\&B Manager) \\
\hline \multicolumn{2}{|c|}{ Marsa Alam: } \\
\hline ILR 3M & 5 Star & 2 (Ex. Chef, and F\&B Manager) \\
\hline IPGR 3M & 5 Star & 2 (Ex. Sous Chef, and Assistant F\&B Manager) \\
\hline CR 3M & 4 Star & 2 (Ex. Chef, and F\&B Manager) \\
\hline
\end{tabular}




\begin{tabular}{|l|l|l|}
\hline PCSBR 3M & 4 Star & 3 (Ex. Chef, Sous Chef and Asst. F\&B Manager) \\
\hline BLH 3M & 3 Star & 2 (Ex. Chef, and Assistant F\&B Manager) \\
\hline MAR 3M & 3 Star & 2 (Sous Chef, and Assistant F\&B Manager) \\
\hline Total & & 39 \\
\hline
\end{tabular}

\section{2- Personal observation checklist:}

The personal observation checklist was designed to assessing the procedures followed to avoid the risk of food allergies in the food and beverage sector within lodging establishments of Red Sea Governorate. The checklist was divided into the following sections:

1-During the reception and registration of guests

2-During the guest's introductory lecture

3 -Inside the restaurants and other service beverage areas

4-Inside the kitchen

5-Inside the food and beverage menus

The personal observation checklist comprises thirty-six questions. For the checklist, a scale of four categories was used to evaluate the sub attributes as follow: (1- Three points for good level; 2- Two points for fair level; 3- One point for poor level; and 4- Zero for absent attribute). The personal observation checklist was also, reviewed by two experts in the field of hotel education as well as three experts in the field of quality and safety inspection of hotels on safety procedures and quality of services provided. Finally it has been completed the personal observation checklist in the period between February and until May 2017. Also, for ethical considerations, the study was used coded names for the investigated hotels.

\section{Results and discussion}

\section{The personal interviews analysis}

Descriptive analysis was used to analyze the data obtained through the personal interviews conducted. The following paragraphs explain this issue in all the investigated hotels.

Question 1: How can we define the concept of food allergy?

The aim of this question is to identify the extent of the respondents' opinions about their knowledge of the concept of food allergy. The results showed that 24 out of $39(61.5 \%)$ of the total, were aware of the concept of food allergy, while their knowledge with the concept of food allergy was consistent with both Associates MD (2017); Mayo Clinic Staff (2014); and FDA (2004) when they defined the food allergy. While the remaining percentage, a number of 15 out of $39(38.5 \%)$ of the respondents were not aware of the concept of food allergy. The analysis also showed that the percentage of knowledge of the concept of food allergy was high in the five-star hotels, followed by the four-star hotels while the three-star hotels ranked last.

Question 2: Are you aware that there are procedures imposed by the hotel on tourism companies that deal with them to the importance of inform the hotel about the guests who have food allergy before arriving to the hotel?

The purpose of this question was to find out if there are procedures imposed by the hotel on tourism companies about the importance of inform the hotel about the guests who have food allergy before arriving to the hotel. The results of the analysis of this question showed that 21 out of $39(53.9 \%)$ of the respondents stated that they were not aware of this matter. While, there were 18 out of $39(46.1 \%)$ of the respondents, stated they already aware that there are procedures imposed by the hotel on tourism companies about the importance of inform the hotel about the guests who have food allergy before arriving to the hotel. It should also be emphasized here that the majority of the respondents who were aware that there are procedures imposed by the hotel on tourism companies regarding the food allergy were 
employees of the five-star hotels and then followed by employees of the four-star hotels and lastly the employees of three-star hotels.

Question 3: Do you think that it is important to the tourism companies' contract should include clear items that dictate the importance of inform the hotel about guests who have food allergy?

This question aims to identify the opinion of the interviewers about the importance and necessity of the tourism companies' contract should be include clear items that dictate the importance of inform the hotel about food allergy cases. The results of the analysis of this question indicate that the great majority of the respondents were 37 of the total $39(95 \%)$ agree on the importance and necessity of the tourism companies' contract should be include clear items that dictate the importance of inform the hotel about food allergy cases. While, 2 out of a total of $39(5 \%)$ of the respondents were reported that was not importance and necessity of the tourism companies' contract should be include clear items that dictate the importance of inform the hotel about food allergy cases.

Question 4: Are the guests asked about if they have food allergy during reception and registration procedures or does at least the registration forms contain this question?

The purpose of this question is to identify if guests were being asking about if they have food allergy during reception and registration procedures in the hotel or if the registration forms contain this question. The results of the analysis of this question showed that there were 21 out of $39(55 \%)$ of the respondents stated that already the guests were asked about if they have food allergy during the reception and registration procedures in the hotel and the registration forms were contain this question. While, confirmed the remaining 18 of $39(45 \%)$ of the respondents that there is no question to the guests that if they have any type of food allergy during the reception and registration procedures in the hotel and the registration forms without this question. On the other hand, there were 12 out of 18 respondents $(100 \%$ of the total respondents in three-star hotels), in addition to 5 out of 18 four-star hotels, while, only 1 out of 18 respondents from five-star hotels.

Question 5: Are there introductory lectures were hotel official with guests to explain the hotel's concern about food allergies?

The purpose of this question was to find out if there are introductory lectures by any hotel official with guests to explain the hotel's concern about food allergies. The results shows that $100 \%$ of the respondents stated that there is no introductory lectures by any hotel official with guests to explain the hotel's concern about food allergies. While some of them added that guests who have food allergy were often interested in making sure they are provided with food and beverage items.

Question 6: Are there any signboards indicate the non-responsibility of the hotel about the food allergy risk and the importance of the guest's attention to this matter?

The main objective of this question is to determine if there are any signboards indicate guidelines and explain to the non-responsibility of the hotel about the risk food allergy and the importance of the guest's attention to this matter. There were 30 of 39 (77\%) of the respondents stated that there was no signboards indicate the non-responsibility of the hotel about the food allergy risk and the importance of the guest's attention to this matter. While, 9 out of $39(23 \%)$ of the total respondents indicated that there signboards indicate to the nonresponsibility of the hotel about the food allergy risk and the importance of the guest's attention to this matter. This shows that the hotel management should be taking into account the provision signboards, especially in restaurants and other places of food and beverage service explains the food allergy risk and the non- responsibility of the hotel about food allergy risk and the importance of the guest's attention to this matter. 
Question 7: Are all items in the menus or displayed on the buffet have a label and showing the name and components of the item, and if it contains ingredients related to food allergy be distinct and written more than one language?

This question aims to identify if all items in the menus or displayed on the buffet have a label and showing the name and components of the item, and if it contains ingredients related to food allergy be distinct and written more than one language. All respondents (100\%) agree that it was not fully observed that food menus are often written by using the item name only. Sometimes a simple explanation can be added to the ingredients of the item only, while the label on the buffet is always containing the item name only, as well as the menus are always written in English only, and that there are no signs distinguish components that are related to food allergy. It should be noted here that the hotel management must be careful to take into consideration that the food menu components of the category, and if they contain items that can cause the sensitivity of food must be written and distinctive, and should be written lists more than one language, especially the language of guests, in addition to observing the rules of menu planning and avoiding problems related to food allergies. This not contrasts with the recommended by Foskett et al. (2003) and The Food Allergy \& Anaphylaxis Network (2010) when declared the importance of taking into account the explanation of items when planning menus to avoid food allergy risks.

Question 8: Are the kitchen and service staff aware with the concept of food allergy and how much it dangerous?

The main aim of this question was that if the kitchen and service staff aware with the concept of food allergy and how much it dangerous. There were 29 out of $39(74.4 \%)$ of the respondents highlighted that they had a lack of knowledge and awareness of the staff of the kitchen and service about food allergy concept and how much it dangerous. While, 10 out of $39(24.6 \%)$ of the respondents stated that the kitchen and service staff have knowledge and awareness of the concept of food allergy and it's dangerous. Therefore, it was important to pay attention to training and awareness among kitchen and all the food and beverage staff to avoid the risk of food allergy. This not consistent with the recommended by The Food Allergy \& Anaphylaxis Network (2010) when mentioned that the importance of ensure all employees understanding food allergy policy and how to avoid the food allergy risks.

Question 9: Are all service staff familiar with varieties of food and beverage that provided in terms of ingredients and cooking method and especially ingredients that can lead to food allergies?

The main objective of this question is to identify if the service staff familiar with varieties of food and beverage provided in terms of ingredients and cooking method, especially components that might cause food allergy. The majority of respondents agreed 33 of 39 $(84.6 \%)$ that the staff were not familiar with varieties of food and beverage provided in terms of ingredients and cooking method, especially components that cause food allergy. While, 6 out of $39(15.4 \%)$ of the respondents agreed that their service staff were aware of the food and beverage items provided in terms of ingredients and the cooking method, that could cause allergy. Therefore clear that need to pay attention to training and to raise awareness among service staff to avoided food allergy risk. This finding was not agreed with McKeever (2014) when stated that the importance of familiarity service staff with components of food items provided.

Question 10: Are all kitchen staff fully aware of the ingredients in terms of ingredients, cooking method and especially those might lead to food allergies?

The main objective of this question is to identify if the kitchen staff familiar with food and beverages items provided in terms of ingredients and cooking method, especially components that could cause food allergy. There were 24 of $39(61.5 \%)$ of the respondents approved that the kitchen staff were not familiar with food and beverage items provided in terms of 
ingredients and cooking method, especially components that lead to food allergy. While, 15 of $39(38.5 \%)$ of the respondents added that the kitchen staff familiar with food and beverage items provided in terms of ingredients and cooking method, that might lead to food allergy. Question 11: Are there training programs offered about the dangers of food allergies?

This question aims to identify if there was an interest in providing training programs for employees about the dangers of food allergies. $100 \%$ of respondents agreed that there were no customized training programs on food allergies. This finding shows that the hotel management should take this into consideration to avoid this type of risk. This was not agreed with The Food Allergy \& Anaphylaxis Network (2010) when stressed the importance of training.

Question 12: Are all the kitchen and service staff were aware with the concept of CrossContact and is this risk avoided during the steps of preparation, cooking and service?

The purpose of this question is to identify if the kitchen and service staff were aware with the concept of Cross-Contact, and if this risk was avoided during the steps of preparing, cooking and service. $100 \%$ of respondents agree that kitchen and service staff were not aware of the concept of Cross-Contact, although some of the respondents were confusing the concept of Cross-Contact and the concept of cross-contamination. Therefore, they were not on the procedures to avoid this risk during the steps of preparing, cooking and service. This result indicates the importance of taking this into account by providing appropriate training programs to ensure proper handling of food allergy risks. This finding was not agreed with FSRE (2016) and FDA (2017) when they explained the importance of knowing and understanding the Cross-Contact risk.

Question 13: Are food allergies considered while selecting food items and ingredients?

The main objective of this question was to know if the food allergy risks considered while selection of food items and their components. There were 27 of $39(69.2 \%)$ of respondents stated that the risk of food allergies was not considered during the selection of food items and its ingredients. On the contrary, 12 of $39(30.8 \%)$ of respondents declared that the risk of food allergies was indeed taken into consideration when selecting food items and ingredients.

Question 14: Are there special menus for those who suffer food allergy?

The real objective of this question was to determine if the hotel offers special menus including allergic food. $100 \%$ of the respondents agreed that they do not have specific food menu written for those who suffer food allergy, where they often agreed with those who were allergic to food on the type of their meals and work to ensure that it provides them with proper and decent way.

Question 15: Have you suggestions or recommendations?

The aim of this question is to identify the point of view of the respondents on the subject of the study and get a number of suggestions or recommendations which they can contribute to the work to control the problems caused by the risk of food allergy in the hospitality industry. This can summarize these suggestions or recommendations were as follows:

- Need to provide training programs to raise awareness of the risk of food allergy and how to proper deal with this risk.

- Need to impose specific standards for quality of service and hotel performance, especially in the manner of dealing properly with the risk of food allergies.

- It is necessary to ensure that the contracts for dealing with tourism companies must be include a number of conditions by which to reduce the problems caused by the risk of food allergies, and these conditions, "requiring guests and tourism companies to inform the hotel about guests who are allergic to food".

- Need to impose the publication of signboards that warn of the risk of food allergies, especially in areas of food and beverage service, and be written clear and in more than one language. 
- The hotel management should take advantage of the introductory lectures in an effective manner and speak directly with the guests through a qualified person about the hotel's issues and problems such as food allergies.

- Need to train and aware those responsible for the planning of food and beverage menus about the danger of food allergy and ways to deal and avoid this risk.

\section{The personal observation checklist analysis}

The personal observation checklist was divided into five sections which were as follows:

1- During the reception and registration of guests: this section included 5 questions: (1Are the guests asked about if they have any kind of food allergy?; 2- Are the front office staff was initiators of the question about food allergies?; 3- If asked about allergies are there any special measures to deal with these situations?; 4- Is any specific document was available for who have a food allergy?; and 5- Are there communicate with the relevant departments, and tell them about who have food allergy?).

2- During the guest's introductory lecture: this section included 4 questions: (1- Is there an introductory lectures where the hotel official involved to explain what the hotel matters?; 2- Are the guests were asked about if they have any kind of food allergy?; 3- Is emphasis was placed on the procedures that taken by hotel to control food allergy risk?; and 4- Are confirmed that the guests should inform the hotel staffs if they have food allergy, and make sure what they are eating or drinking during the period of stay?).

3- Inside the restaurants and other service beverage areas: this section included 12 questions: (1- Are there any signboards indicate the lack of the hotel responsibility about food allergy risk?; 2- Are there any signboards describes the food allergy risk, and need to confirm the guests of what they eat or drink?; 3- Are all food items offered on the buffet have a label and describes the product name?; 4- Is the label shown the food item components?; 5- If yes, Is there any difference between ingredients that are related to food allergy risk such as flour, nuts and other from ways of writing, font size, color, etc.?; 6- Is the food label was written by more than one language?; 7- Are service staff clearly aware of food allergy risk?; 8- Are the service staff familiar with food and beverage items that provided in terms of ingredients?; 9- Are the service staff familiar with food and beverages items that provided and they contain components related to food allergy?; 10- Are the service staff aware and familiar with the concept of Cross-Contact?; 11- Is the risk of Cross-Contact avoided during the preparation and service of food and beverage items?; and 12- Are training programs offered on food allergy for all service staffs?).

4- Inside the kitchen: this section included 10 questions: (1- Are all chefs especially those standing behind the buffet fully aware with food items in terms of ingredients and cooking methods?; 2- Are all chefs especially those standing behind the buffet well acquainted with a foreign language at least?; 3- Are all the chefs especially those standing behind the buffet fully aware with the concept of food allergy risk?; 4- Are all chefs especially those standing behind the buffet familiar with the food items offered and what ingredients contain food allergies?; 5- Are all chefs especially those standing behind the buffet fully aware with the concept of Cross-Contact?; 6- Is the Cross-Contact risk avoided during the preparation and cooking of food items?; 7- Are training programs offered on food allergy for all chefs?; 8- Is the food allergy risk taken into consideration when planning food menu and ingredients?; 9- Is there a separation in the tools and equipment that used in preparing and cooking meals for guests who have food allergy?; and 10- Are there trained and specific chefs for handling with meals of the guests that have food allergy?). 
5- Inside the food and beverage menus: this section included 5 questions: (1- Are all the food and beverage menus contain the name and components of items?; 2- If yes, Is there any clarification or differentiation of ingredients related to food allergy such as flour or nuts, etc.?; 3- Are all the food and beverage menus written by more than one language?; 4- Are the food and beverage menus clear in terms of size, color and font type?; and 5Are there special menus for the guests who have food allergy?).

Table 5 shows the findings of personal observation checklist, all attributes were evaluated as following: 1) During the reception and registration of guests: this part was evaluated by 5 questions in a total of 15 as maximum scores (3 marks per question), 2) During the guest's orientation lecture: this part was evaluated by 5 questions in a total of 15 as maximum scores (3 marks per question), 3) Inside the restaurants and other service beverage areas: this part was evaluated by 11 questions in a total of 33 as maximum scores ( 3 marks per question), 4) Inside the kitchen: this part was evaluated by 10 questions in a total of 30 as maximum scores (3 marks per question), 5) Inside the food and beverage menus: this part was evaluated by 5 questions in a total of 15 as maximum scores ( 3 marks per question).

Table 5: Findings of personal observation checklist

\begin{tabular}{|c|c|c|c|c|c|c|c|}
\hline & & Reception & Orientation & Restaurants & Kitchen & Menus & \\
\hline & & 15 & 15 & 33 & 30 & 15 & 108 \\
\hline & & & ghada Desti & ation & & & \\
\hline PSHR 1H & A. Score & 10 & 10 & 18 & 15 & 8 & 61 \\
\hline $5 \mathrm{Star}$ & $\%$ & 66.7 & 66.7 & 54.6 & 50 & 53.3 & 56.5 \\
\hline MRSEG 1H & A. Score & 12 & 11 & 20 & 18 & 10 & 71 \\
\hline 5 Star & $\%$ & 80 & 73.3 & 60.6 & 60 & 66.7 & 65.7 \\
\hline$\overline{\mathrm{AA} 1 \mathrm{H}}$ & A. Score & 8 & 8 & 15 & 16 & 7 & 54 \\
\hline 4 Star & $\%$ & 53.3 & 53.3 & 45.5 & 53.3 & 46.7 & 50 \\
\hline MIBR 1H & A. Score & 8 & 7 & 13 & 12 & 7 & 47 \\
\hline $4 \mathrm{Star}$ & $\%$ & 53.3 & 46.7 & 39.4 & 40 & 46.7 & 43.5 \\
\hline HMBHR 1H & A. Score & 7 & 7 & 10 & 10 & 8 & 42 \\
\hline $3 \mathrm{Star}$ & $\%$ & 46.7 & 46.7 & 30.3 & 33.3 & 5.3 & 38.9 \\
\hline HJV 1H & A. Score & 7 & 6 & 11 & 10 & 6 & 40 \\
\hline 3 Star & $\%$ & 46.7 & 40 & 33.3 & 33.3 & 40 & 37 \\
\hline & & & useir Destina & ion & & & \\
\hline DBR 2Q & A. Score & 9 & 8 & 18 & 14 & 8 & 57 \\
\hline 5 Star & $\%$ & 60 & 53.3 & 54.6 & 46.7 & 53.3 & 52.8 \\
\hline RSR 2Q & A. Score & 10 & 9 & 20 & 16 & 8 & 63 \\
\hline $5 \mathrm{Star}$ & $\%$ & 66.7 & 60 & 60.6 & 53.3 & 53.3 & 58.3 \\
\hline FBR 2Q & A. Score & 7 & 9 & 14 & 12 & 7 & 49 \\
\hline $4 \mathrm{Star}$ & $\%$ & 46.7 & 60 & 42.4 & 40 & 46.7 & 45.4 \\
\hline MR 2Q & A. Score & 8 & 6 & 15 & 13 & 8 & 50 \\
\hline 4 Star & $\%$ & 53.3 & 40 & 45.5 & 43.3 & 53.3 & 46.3 \\
\hline MBR 2Q & A. Score & 6 & 3 & 10 & 9 & 4 & 32 \\
\hline 3 Star & $\%$ & 40 & 20 & 30.3 & 30 & 26.7 & 29.6 \\
\hline UBC 2Q & A. Score & 5 & 5 & 11 & 11 & 5 & 37 \\
\hline 3 Star & $\%$ & 3.3 & 33.3 & 33.3 & 36.7 & 33.3 & 34.3 \\
\hline & & & a Alam Dest & nation & & & \\
\hline ILR 3M & A. Score & 11 & 10 & 20 & 18 & 10 & 69 \\
\hline $5 \mathrm{Star}$ & $\%$ & 73.3 & 66.7 & 60.6 & 60 & 66.7 & 63.9 \\
\hline IPGR 3M & A. Score & 10 & 10 & 20 & 20 & 10 & 70 \\
\hline $5 \mathrm{Star}$ & $\%$ & 66.7 & 66.7 & 60.6 & 66.7 & 66.7 & 64.8 \\
\hline CR 3M & A. Score & 6 & 6 & 15 & 12 & 6 & 45 \\
\hline 4 Star & $\%$ & 40 & 40 & 45.5 & 40 & 40 & 41.7 \\
\hline PCSBR 3M & A. Score & 7 & 6 & 17 & 15 & 6 & 51 \\
\hline
\end{tabular}


International Journal of Heritage, Tourism and Hospitality Vol. (11), No. (2/2), September, 2017

By: Faculty of Tourism and Hotels, Fayoum University

\begin{tabular}{|l|c|c|c|c|c|c|c|}
\hline 4 Star & $\%$ & 46.7 & 40 & 51.5 & 50 & 40 & 47.2 \\
\hline \multirow{2}{*}{$\begin{array}{l}\text { BLH 3M } \\
\text { 3 Star }\end{array}$} & A. Score & 4 & 3 & 11 & 10 & 5 & 33 \\
\cline { 2 - 8 } $\begin{array}{l}\text { MAR 3M } \\
\text { 3 Star }\end{array}$ & A. Score & 26.7 & 20 & 33.3 & 33.3 & 33.3 & 30.6 \\
\cline { 2 - 8 } & $\%$ & 33.3 & 26.7 & 36.4 & 33.3 & 33.3 & 33.3 \\
\hline
\end{tabular}

$*$ A. Score $=$ Actual Score

The illustrated data in Table 5 shows that the investigated hotels/destinations were arranged as follows: Where it was the first rank hotel MRSEG $1 \mathrm{H}$, a five-star hotel located in the Hurghada destination, which achieved 71 points, a total of 108 points, and by percentage of $65.7 \%$. Then it came in the second rank hotel IPGR 3M, a five-star hotel located in the Marsa Alam destination where achieved 70 points, and by percentage of $64.7 \%$. Also, it was came in third rank hotel ILR 3M, a five-star hotel located in the Marsa Alam which achieved 69 points and by the percentage of $63.9 \%$. While was ranked fourth hotel RSR 2Q is a five-star hotel and located in Quseir destination where achieved 63 points and by percentage of $58.3 \%$. Also, the PSHR 1H hotel came the fifth ranking, it was a five-star hotel located in Hurghada destination where achieved a 61 point by percentage of $56.5 \%$. And followed by the DBR $2 \mathrm{Q}$ hotel in the sixth rank, a five- star hotel located in Quseir destination, where it achieved 57 points with $52.8 \%$. Then came in the seventh ranking AA $1 \mathrm{H}$ hotel is a four-star hotel and located in Hurghada destination where it was achieved 54 points and by $50 \%$. While it was ranked eighth PCSBR 3M hotel, a four-star hotel and located in the Marsa Alam destination where achieved 51 points, and by percentage of $47.2 \%$.

Meanwhile, the MR 2Q hotel come in the ninth rank, it was a four-star hotel and located in Quseir destination which achieved 50 points and 46.3\%. Also, the FBR 2Q hotel come in the tenth rank, it was a four-star hotel and located also in Quseir destination where it was achieved 49 points and $45.4 \%$. But, the MIBR $1 \mathrm{H}$ hotel come in the eleventh rank, and it also four-star hotel but located in Hurghada destination, where achieved 47 points and $43.5 \%$. Then the CR 3M hotel come in the twelfth rank, and it also four-star hotel but located in Marsa Alam destination, where achieved 45 points and $41.7 \%$. While it was ranked thirteenth HMBHR 1H hotel, a three-star hotel and located in the Hurghada destination where achieved 42 points, and by percentage of $38.9 \%$. And followed by the HJV $1 \mathrm{H}$ hotel in the fourteenth rank, a three-star hotel located in Hurghada destination, where it achieved 40 points with $37 \%$. Also, followed by the UBC 2Q hotel in the fifteenth rank, a three-star hotel and located in the Qusier destination where achieved 37 points, and by percentage of 34.3\%. Moreover, the MAR 3M hotel come in the sixteenth rank, and it also three-star hotel and located in Marsa Alam destination, where achieved 36 points and 33.3\%. And it was came in seventeenth rank the BLH 3M hotel and it was a three-star hotel and located in Marsa Alam destination, where achieved 33 points and 30.6\%. While, the MBR 2Q hotel was came in the eighteenth and final rank, and it was three-star hotel and located in Qusier destination, which achieved 32 points and $29.6 \%$ of the total score.

\section{The personal interviews and personal observation checklist findings}

The results concluded from the analysis of the personal interviews and personal observation checklist applied on the investigated destination/hotels. The main results can be summed as follows:

- All of the investigated hotels need to pay attention to study and monitor the control of the risk of food allergy and work to apply all precautions to be followed to control this matter.

- There is an urgent need to pay attention to the training and awareness of hotel's employees on the importance of avoiding the dangers of food allergies and follow the correct/proper procedures to deal with this risk. 
- The result shows that the level of five-star hotels in the investigated hotels was somewhat better than the four and three star hotels the awareness of food allergies risk.

- The results also indicate that the four-star hotels in the investigated hotels were also somewhat better than the three-star hotel the awareness of food allergies risk.

- Finally, the result shows that the three-star hotels in the investigated hotels were at a level below the average, which indicates the need to increase awareness and attention to the risk of food allergies.

\section{Conclusions and Recommendations}

It should be emphasized that the results of this research cannot be circulated to all hotels in the Red Sea Governorate but, only the research samples. This research shows that there was a need to pay attention to highlight the importance of the risk of food allergies, and identify effective and appropriate ways to control this potential danger. The study also shows that there was a decrease in the level of knowledge and awareness of the hotel staff in the investigated hotels on the risk of food allergy, as well as knowing how to properly deal with this risk in order to ensure the safety of guests and reduce the problems that facing the hospitality industry. The study also highlighted the importance of developing appropriate requirements and rules when contract and cooperate with tourism companies and guests in order to reduce these problems. There was also a need to apply procedures that can be ensure satisfied and safety for the guests, and not waste the right of the hotel by taking care to spread awareness of employees as well as educates the guests through preparing an introduction lectures for the guests and the publication of signboards in addition to writing menus in a way that can avoid this risk. There is an urgent need to pay attention to the training and awareness of hotel's employees on the importance of avoiding the dangers of food allergies and follow the correct/proper procedures to deal with this risk.

\section{Recommendations}

A number of recommendations can be derived from the above, which may include the following:

\section{First: General recommendations}

- There is a need to find ways to inform the hotel about guests suffering from food allergies in sufficient time before arrival.

- Public awareness should be promoted of the food allergy risk especially in the hotel education field.

- There is a need to impose specific standards/procedures for quality of service and hotel performance, especially in the manner of dealing properly with the risk of food allergies.

\section{Second: Recommendations for hotels}

- It is important to ensure that guests during the check-in procedure at the hotel that it is important to report if they have food allergies.

- The hotel management should provide specialized training programs on the risk of food allergy.

- The hotel management should take care to set appropriate conditions and rules for contracting and cooperation with tourism companies and guests in order to reduce these problems.

- The need to provide a plan for dealing with emergencies related to food allergy.

- Preferably customize a qualified person and preferably to be managers to deal with guests who suffer food allergy (All employees must be know this person). 
- Hotel should be publication of signboards that warn of the risk of food allergies, especially in areas of food and beverage service, and be written clear and in more than one language.

- Hotel should be train and aware those responsible for the planning of food and beverage menus about the danger of food allergy and ways to deal and avoid this risk.

\section{References}

American College of Allergy, Asthma \& Immunology (2014). Types of Allergies: Food Allergy. Retrieved October 21, 2016, from http://acaai.org/aller gies/types/foodallergy.

Associates MD (2017). Allergy. Associates MD Midical Group. Retrieved August 20, 2017, from http://associatesmd.com/services/allergies.

Basset, W. (2005). What you should know about common food allergies. Cortland Forum, November, 38-45.

Bennion, M., and Scheule, B. (2004). Introductory Food. Twelfth Edition, Peatson Education, Inc., New Jersey, pp. 88-89

Brostoff, J., and Gamlin, L. (2000). Food Allergies and Food Intolerance: The Complete Guide to Their Identification and Treatment. Healing Arts Press. ISBN13: 9780892818754 pp. $12-50$

Byrd-Bredbenner, C., and Maurer, J. (2007). Food Allergies: Safe Food Handling to Prevent Triggering an Allergic Reaction. Retrieved December 21, 2016 Extension Journal, Inc. ISSN 1077-5315, Vol., 45, No., 6 from https://joe.org/joe/2007december/tt6.php.

Egyptian Hotel Association, (2016). Egyptian Hotel Association: The Guide. $35^{\text {th }}$ Edition 2015 - 2016, Cairo, Egypt

FARE, (2016). Avoiding Cross-Contact. Food Allergy Research \& Education, Retrieved October 03, 2016 from https://www.foodallergy.org/cross-contact.

FDA, (2017). Food Allergies: What You Need to Know. U.S. Food \& Drug Administration (FDA), Retrieved August 16, 2017 from https://www.fda.go v/food/ingredientspackaginglabeling/foodallergens/ucm079311.htm.

FDA. (2004). Food Allergen Labeling and Consumer Protection Act of 2004. U.S. Food \& Drug Administration (FDA). August 2, 2004.

Formanek, R. (2001). Food Allergies: When Food Becomes the Enemy. U.S. Food \& Drug Administration (FDA) Consumer, 35 (4)

Foskett, D., Ceserani, V., and Kinton, R. (2003). "The Theory of Catering". 10 ${ }^{\text {th }}$ Edition, Hodder \& Stoughton, London, pp. 189-191, 343

FreeHotelsGuide.com (2016). Egypt Hotels Information Guide. Retrieved February 12, 2016 from: http://www. egypt.freehotelguide.com/.

Massachusetts Department of Health (2010). Memo: Proposed Amendments to 105 CMR 590.000, State Sanitary Code Chapter X: Minimum Sanitation Standards for Food Establishments, to Comply with the Allergen Awareness Act (Word). Massachusetts Department of Health. June 9, 2010.

Mayo Clinic Staff, (2014). Diseases and Conditions: Food allergy. Mayo Foundation for Medical Education and Research, Retrieved November 18, 2016 from http://www.mayoclinic.org/diseases-conditions/foodallergy/basics/definitio n/con20019293.

McKeever, A. (2014). How Restaurant Pros Are Handling the Surge of Food Allergies. Retrieved Jun 19, 2016 from https://www.eater.com/2014/6/19/620719 9/howrestaurant-pros-are-handling-the-surge-of-food-allergies. 
National Institute of Allergy and Infectious Diseases (2013). Food Allergy: An Overview. National Institute of Allergy and Infectious Diseases. Retrieved September 11, 2016 from http://www.niaid.nih.gov/topics/foodallergy/Pages/d efault.aspx.

Nowak-Wegrzyn A. (2013). Clinical manifestations and diagnosis of oral allergy syndrome (pollen-food allergy syndrome). Retrieved September 11, 2016 from http://www.uptodate.com/home.

Sicherer, S. (2006). Understanding and Managing Your Child's Food Allergies. Johns Hopkins University Press, ISBN: 0801884918, pp. 28-66

Sicherer, S. (2013). Food Allergies: A Complete Guide for Eating When Your Life Depends on It. A Johns Hopkins Press Health Book, ISBN: 1421408457, pp. 22, 30, 65

Taylor, L., and Hefle, L. (2001). Food Allergies and Other Sensitivities. Food Technology, 55. (9), 68-81

The Food Allergy \& Anaphylaxis Network, (2006). Food Allergy Training Guide for Hospital and Food Service Staff: A Comprehensive Program for Training Hospital Staff to Safety Prepare and Serve Food to Patients with Food Allergies. ISBN No. 1882541-44-8, pp. 1-70

The Food Allergy \& Anaphylaxis Network, (2010). Welcoming Guests With Food Allergies: A comprehensive program for training staff to safely prepare and serve food to guests who have food allergies. www.foodallergy.org, https://www.foodallergy.org/file/welcoming-guests-faan.pdf, ISBN 1-882541-21-9, pp. $1-60$

Wood, R. (2007). Food Allergies for Dummies. John Wiley \& Sons, USA, ISBN: 0470095849m pp. 183-199 